\title{
Effects of Service Factors and Relationship Quality on Customer's Behavior Intention in Skin-care Shop
}

Min-Joung Kim

Department of Business Administration, Namseoul University, Cheonan-si, Chungcheongnam-do, Korea

Corresponding author: Min-Joung Kim, Department of Business Administration, Namseoul University, 91 Daehak-ro, Seonghwan-eup, Seobuk-gu, Cheonan-si, Chungcheongnam-do 31020, Korea

Tel.: +82 7088812044

Fax: +82 317014131

Email: mj1936@hanmail.net

Received July 27, 2016

Revised September 12, 2016

Accepted September 28, 2016

Published December 30, 2016

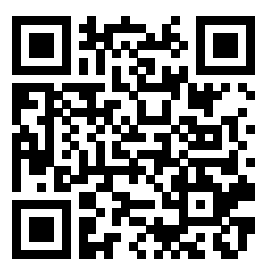

\begin{abstract}
Purpose: This study aims to examine the effects of service factors and relationship quality on customer behavior. Methods: To analyze the data, the statistical package, SPSS Ver. 24, was used. After a frequency analysis, Cronbach's $\alpha$ was used to verify validity and reliability on a selective variable. A principal component and Varimax were used for factor analysis. In addition, multiple linear regression analysis was performed to inspect the impact among variables. Results: The results showed that service factors influenced relationship quality. In particular, corporality in service factors had a crucial impact on relationship quality. A customer's intention to revisit was positively influenced by specialization, market price, and customer orientation, while word-of-mouth intention was influenced by specialization, market price, and corporality. Customer immersion in relationship quality also affected revisit intention and customer satisfaction positively affected word-of-mouth intention, showing that customer behavior was positively influenced by service factors and relationship quality. Revisit intention was influenced by service factors and wordor-mouth intension was positively influenced by service factors and relationship quality. Conclusion: The results showed that skin-care shops have a great interest increasing revisits by existing customers through specialization, improvement of service quality, satisfaction, and immersion, as well as through material conditions such as a comfortable environment, friendly staff, and more service space.
\end{abstract}

Keywords: Customer behavior intention, Customer satisfaction, Customer immersion, Relationship quality, Word-of-mouth intention

\section{Introduction}

경제발전과 더불어 여성들의 활발한 사회진출은 패션과 외모 등 외적 아름다움에 대한 기대와 욕구를 증대시켰다. 2000년대 이후 피부미용산업은 서비스산업의 중요한 영역으로 발전되었고 양적인 측면에서도 비약적인 성장을 이루었다. 반면 업체 간의 고객확보에 대한 경쟁이 한층 치열해짐에 따라 많은 업체들은 생존을 위해 고 객과의 지속적인 관계유지와 고객만족 등 관계마케팅을 통한 수익 창출에 많은 관심을 두고 있다.

관계마케팅이란 거래당사자간의 관계를 중심으로 거래나 교환 이 장기적으로 지속되도록 해서 당사자 모두가 이익을 보도록 한다 는 개념으로(Yi, 2004), 관계마케팅의 핵심은 신규 고객을 창출하 기보다는 고객만족을 통한 기존 고객의 감소를 방지하여 장기적으 로 고객과의 관계를 유지· 발전시키는 것으로, 피부미용서비스업
처럼 인적자원과 기술 의존도가 높은 전문분야에서는 관계마케팅 의 효과적인 이행을 통한 고객만족을 높여 기존 고객의 충성도를 증대시킬 수 있는 경영 전략이 필요하다(Nam \& Seong, 2014).

피부미용시장이 성숙되고 경쟁이 심화된 환경에서는 새로운 고객 을 찾으려는 노력보다는 기존의 고객을 유지하고 충성도를 높이는 것 이 효율적인 방법이다(Oliver, 1981). 고객만족도가 높아지면 기존 고객 의 충성도는 높아지는 반면 가격 민감도는 낮아져 경쟁적 상황에서 기 존 고객을 보호하게 되며, 미래의 거래비용을 낮추어 실패비용을 절감 시키고 신규 고객의 유치비용을 감소시킨다. 이는 기업의 이미지와 평 판을 높여 장기적으로 기업에게 높은 수익성을 보장한다(Yi, 2000).

피부미용서비스와 같은 서비스업에서는 단기적인 관계가 아니 라 구매자와 판매자 간의 장기적인 관계가 고객의 욕구를 보다 잘 충족시키고 상호 간의 이익을 증가시킨다(Webster, 1992). 즉, 고 객과의 장기적 관계의 기본적인 면을 고객과의 관계유지의 증대 
로 보고 있으며, 신규 고객을 창조하는 것보다 기존 이용고객을 유 지하는 것이 훨씬 적은 비용이 지출되고 고객과의 장기적인 관계 를 유지하는 것이 기업의 수익을 창출할 수 있는 원천으로 보았다 (Reichheld \& Sasser, 1990). 또한 서비스 제공자와 고객과의 장기 적인 유대관계를 형성하고 지속적으로 유지 · 발전시키는 데 중점 을 둔 고객만족 마케팅을 통해(Choe \& Rou, 2007), 상호 개방성과 협력적 의도로 서비스 제공자와 고객이 자유롭게 의사소통을 하는 등 쌍방간의 역동적 작용이 중시되어야 한다(Crosby et al., 1990).

관계마케팅의 실행요인으로 Grönroos (1990)는 고객유지 중시, 제품효익 지향, 장기간 평가, 고객서비스 강조, 고객의 높은 몰입, 고객과의 높은 유대, 품질 우선 등의 7가지를 제시하였고, Morgan \& Hunt (1994)는 관계마케팅 실행요인이 소매업체에 대한 만족도 에 긍정적인 관계가 있다고 하였으며, DuPont (1998)와 Grönroos (1994)도 같은 결과를 보고하며, 관계마케팅 실행요인과 고객만족 은 긍정적 관계가 있음을 보여주었다. Park (2010)은 전문성과 고객지
향성은 각각 고객만족 및 고객신뢰에 긍정적인 영향을 미친다고 하 였으며, Hwang \& Hwang (2005)은 미용서비스를 이용하는 고객이 인지한 미용서비스 제공자의 서비스 품질은 고객만족에 정(+)의 영 향을 준다고 밝히고 고객과의 장기적인 관계형성에 있어서 가장 중요 한 것은 고객과 종업원 간의 관계라고 제시하였다. 또한 Andreassen \& Lindestad (1998)는 고객만족을 높임으로써 고객 충성도를 높일 수 있다고 하였고, $\operatorname{Han}$ (2004)은 서비스 품질이 높을수록 관계요인인 만 족, 신뢰, 몰입이 높아지며, 만족, 신뢰, 몰입이 높을수록 고객유지와 긍정적 구전 효과가 높아지고 있음을 보고하였다.

본 연구는 피부미용실에서의 관계마케팅을 다양한 관점에서 고찰 하여 고객과의 장기적인 관계를 위해 필요한 피부미용서비스를 제 시하고 이들이 고객만족을 비롯한 고객행동의도에 미치는 영향을 조사하여 피부미용실에 적합한 서비스 전략을 제시하는데 그 목적 이 있다.

\section{Table 1. General characteristics of subjects}

\begin{tabular}{|c|c|c|c|}
\hline & Status & Frequency & $\%$ \\
\hline \multirow{2}{*}{ Sex } & Male & 38 & 15.3 \\
\hline & Female & 210 & 84.7 \\
\hline \multirow{4}{*}{ Age } & Under 20 & 110 & 44.4 \\
\hline & $30 \mathrm{~s}$ & 81 & 32.7 \\
\hline & $40 \mathrm{~s}$ & 40 & 16.1 \\
\hline & Over 50 & 17 & 6.9 \\
\hline \multirow{4}{*}{ Scholarship } & High school diploma & 37 & 14.9 \\
\hline & College graduate & 66 & 26.6 \\
\hline & University graduate & 116 & 46.8 \\
\hline & Over graduate school & 29 & 11.7 \\
\hline \multirow{4}{*}{ Income } & 1 million won to 2 million won & 101 & 40.7 \\
\hline & 2 million won to 3 million won & 93 & 37.5 \\
\hline & 3 million won to 4 million won & 31 & 12.5 \\
\hline & Over 4 million won & 23 & 9.3 \\
\hline
\end{tabular}

\section{Table 2. The contents of questionnaire}

\begin{tabular}{|c|c|c|c|c|}
\hline & Status & Contents & Item & Quiz form \\
\hline \multirow{2}{*}{$\begin{array}{l}\text { Background } \\
\text { variable }\end{array}$} & \multirow{2}{*}{$\begin{array}{l}\text { Character of } \\
\text { those surveyed }\end{array}$} & Use realities & 5 & \multirow{2}{*}{$\begin{array}{l}\text { Multiple choice } \\
\text { method }\end{array}$} \\
\hline & & Population statistics & 4 & \\
\hline \multirow{6}{*}{$\begin{array}{l}\text { Independent } \\
\text { variable }\end{array}$} & \multirow{4}{*}{$\begin{array}{l}\text { Service } \\
\text { factors }\end{array}$} & Specialization & 4 & \multirow{6}{*}{$\begin{array}{l}\text { Likert } \\
5 \text { scales }\end{array}$} \\
\hline & & Market price & 4 & \\
\hline & & Corporality & 4 & \\
\hline & & Customer orientation & 4 & \\
\hline & \multirow{2}{*}{$\begin{array}{l}\text { Relationship } \\
\text { quality }\end{array}$} & Customer satisfaction & 3 & \\
\hline & & Customer immersion & 2 & \\
\hline \multirow{2}{*}{$\begin{array}{l}\text { Dependent } \\
\text { variable }\end{array}$} & \multirow{2}{*}{$\begin{array}{l}\text { Behavior } \\
\text { intention }\end{array}$} & Revisit & 3 & \multirow{2}{*}{$\begin{array}{l}\text { Likert } \\
5 \text { scales }\end{array}$} \\
\hline & & Word-of-mouth intention & 2 & \\
\hline
\end{tabular}




\section{Methods}

\section{1. 연구대상}

본 연구는 경기도 성남지역에서 피부미용실을 이용하는 고객을 대상으 로 설문조사를 실시하였다. 조사기간은 2016년 5월 15일부터 5월 30일까 지 15 일간이었으며, 설문지는 응답자가 직접 기입하는 자기평가기입방식 을 이용하였다. 총 300 부의 설문지 중불성실한응답및 신뢰성이 낮다고 판단되는 52 부의 설문지를 제외하고 총 248 부 설문지를 실증분석 자료 로 사용하였으며, 조사대상자의 인구통계학적 특성은 Table 1과같다.

\section{2. 연구내용 및 방법}

1) 설문지의 구성

설문지는 일반적인 조사대상자의 특징으로 피부마용실 이용실태 5 개 문 항 및 인구통계 4 문항, 피부미용실의 서비스요인 16 문항, 관계품질 5 문항, 행동의도 5 문항등총 35 개문항으로구성하여설문을실시하였다. 측정항목 들은 1 (전혀 그렇지 않다)에서 5 (매우 그렇다)까지의 범위를 갖는 Likert 5 점 척도를사용하였다. 본연구의 설문지 구성내용은 Table 2 와 같다.

\section{2) 자료분석방법}

설문조사에서 회수된 설문지 응답결과를 통계 패키지 프로그램인 SPSS Statistics (Ver. 24; IBM, USA)를 이용하여 설문지의 타당성과 신뢰 도를 확인 후, 먼저 조사대상자들에 대한 피부마용실 이용실태를 조사하 기 위하여 빈도분석을 실시하였고, 변수 선정의 타당성 및 신뢰성을 검증 하기 위하여 Cronbach's $\alpha$, 요인분석을 위해 주성분 분석법과 베리멕스 (Varimax)를 사용하였다. 또한 변수들 간의 영향을 파악하기 위하여 다 중회귀분석을 실시하였다.

\section{Results and Discussion}

\section{1. 설문지의 타당성과 신뢰도 및 피부미용실 이용실태 분석}

1) 설문지의 타당성과 신뢰도

본 연구에서는 설문지의 문항에 대한 타당성 검증 및 공통요인을 찾아내 변수로사용하기위해요인분석을실시하였으며, 요인회전과관련하여베리멕 스회전(Varimax rotation)을실시하였다. 신뢰도검증을위해서는Cronbach's $\alpha$ 계수를산출하였고 Cronbach's $\alpha$ 값은 0.949로 높은 신뢰도를 보였다.

Table 3. Analysis of the actual conditions of customers utilizing skin-care shop

\begin{tabular}{|c|c|c|c|}
\hline & Status & Frequency & $\%$ \\
\hline \multirow{5}{*}{ Frequency } & Over twice a week & 36 & 14.5 \\
\hline & Once a week & 57 & 23.0 \\
\hline & Every other week & 74 & 29.8 \\
\hline & Once a month & 11 & 4.4 \\
\hline & Irregularly & 70 & 28.2 \\
\hline \multirow{5}{*}{ Period } & Less than one month & 45 & 18.1 \\
\hline & Less than three months & 49 & 19.8 \\
\hline & Less than six months & 64 & 25.8 \\
\hline & Less than one year & 51 & 20.6 \\
\hline & Over one year & 39 & 15.7 \\
\hline \multirow{4}{*}{ Spending } & 10,000 won to 50,000 won & 42 & 16.9 \\
\hline & 50,000 won to 100,000 won & 45 & 18.1 \\
\hline & 100,000 won to 150,000 won & 110 & 44.4 \\
\hline & Over 150,000 won & 51 & 20.6 \\
\hline \multirow{3}{*}{ Type } & Private management (Over two skin-care experts) & 107 & 43.1 \\
\hline & Franchise & 118 & 47.6 \\
\hline & Collaboration with hospitals (Department of dermatology) & 23 & 9.3 \\
\hline \multirow{7}{*}{ Criterion } & Skin-care treatment and facilities & 117 & 47.2 \\
\hline & Skin-care service & 58 & 23.4 \\
\hline & Location and traffic convenience & 26 & 10.5 \\
\hline & Fame & 12 & 4.8 \\
\hline & Recommendation of the surrounding people & 10 & 4.0 \\
\hline & Treatment fee & 22 & 8.9 \\
\hline & Friendly relation with staff & 3 & 1.2 \\
\hline
\end{tabular}


2) 피부미용실 이용실태 분석

피부미용실의 고객이용실태는 Table 3 과 같다. 이용빈도는 2 주 1 회가 74 명 $(29.8 \%)$ 으로 가장 많았고 불규칙하게 이용하는 사람이 70 명 $(28.2 \%)$, 주 1 회 57 명(23.0\%), 주 2 회 이상 36 명 (14.5\%), 월 1회 11 명(4.4\%) 순으로 피부미용실을 이용하는 것으 로 조사되었다. 이용기간은 6개월 미만 64명(25.8\%), 1년 미만
51 명(20.6\%), 3개월 미만 49명(19.8\%), 1개월 미만 45명(18.1\%), 1 년 이상 39 명 $(15.7 \%)$ 순으로 높은 비율을 차지하였다. 지출비용 은 10-15만원이 110 명(44.4\%)으로 가장 많았으며 그 뒤를 15 만원 이상 51명(20.6\%), 5-10만원 45명(18.1\%), 1-5만원 42명(16.9\%) 순이었다. 피부미용실의 이용 유형으로는 프랜차이즈 118 명 (47.6\%)와 개인 경영(2인 이상) 107 명(43.1\%)로 유사했으며, 병원

Table 4. Analysis of validity and reliability on service factors

\begin{tabular}{|c|c|c|c|c|}
\hline \multirow{2}{*}{ Status } & \multicolumn{4}{|c|}{ Ingredients } \\
\hline & Market price & Corporality & Specialization & Customer orientation \\
\hline Activation of various coupon systems & 0.924 & 0.088 & 0.192 & 0.153 \\
\hline Have new costumer's creation program & 0.924 & 0.088 & 0.192 & 0.153 \\
\hline Have policy for price maintenance & 0.881 & -0.026 & 0.229 & 0.270 \\
\hline Construct timed and daily price systems & 0.801 & 0.039 & 0.001 & 0.135 \\
\hline Many of up-to-date equipment & 0.038 & 0.947 & 0.165 & -0.009 \\
\hline Equipped with modern interior design & 0.014 & 0.932 & 0.178 & -0.048 \\
\hline Provide distinguished service & 0.052 & 0.923 & -0.016 & 0.227 \\
\hline Have convenient facilities such as a rest place & 0.057 & 0.898 & -0.017 & 0.280 \\
\hline Recommend skin care to customers & 0.002 & 0.199 & 0.925 & 0.061 \\
\hline Have no side effects after skin care & 0.256 & -0.045 & 0.923 & 0.032 \\
\hline Have a good knowledge of skin care & 0.273 & -0.054 & 0.904 & 0.066 \\
\hline Have a special ability on skin care & 0.071 & 0.210 & 0.888 & 0.095 \\
\hline Make an effort on improving relationship & -0.060 & 0.282 & 0.110 & 0.848 \\
\hline Quickly respond to complaints & 0.463 & -0.082 & 0.151 & 0.815 \\
\hline Regularly monitor customer' complaints & 0.473 & -0.071 & 0.160 & 0.805 \\
\hline Acceptance on complains is easy & 0.244 & 0.310 & -0.099 & 0.736 \\
\hline Eigen value & 6.123 & 3.504 & 2.792 & 1.506 \\
\hline Variance explanation (\%) & 23.612 & 23.246 & 22.296 & 17.881 \\
\hline Cumulative explanation (\%) & 23.612 & 46.858 & 69.153 & 87.034 \\
\hline Credibility & 0.944 & 0.939 & 0.956 & 0.885 \\
\hline
\end{tabular}

\section{Table 5. Analysis of validity and reliability on relationship quality}

\begin{tabular}{lcc}
\hline & \multicolumn{2}{c}{ Ingredients } \\
Status & $\begin{array}{c}\text { Customer } \\
\text { immersion }\end{array}$ & 0.325 \\
Satisfactory service from the staff in skin-care shop & 0.902 & 0.307 \\
Satisfactory environment of skin-care shop & 0.869 & -0.229 \\
Satisfactory utilization of skin-care shop & 0.778 & 0.877 \\
Become a regular customer of skin-care shop & 0.102 & 0.850 \\
Maintain relationship with skin-care shop & 0.088 & 1.378 \\
Eigen value & 2.558 & 34.871 \\
Variance explanation (\%) & 43.840 & 78.711 \\
Cumulative explanation (\%) & 43.840 & 0.721 \\
Credibility & 0.822 & \\
\hline
\end{tabular}


피부과와 제휴된 피부미용실은 23명(9.3\%)으로 조사되었다. 피부 미용실의 선택기준으로는 시술과 시설이 117 명(47.2\%)으로 가장 높은 비율을 차지하였으며, 서비스 58 명(23.4\%), 위치와 교통편 의성 26 명(10.5\%), 시술비용 22 명(8.9\%), 유명세 12 명(4.8\%), 주 변 사람 추천 10 명 $(4.0 \%)$ 순이었으며 직원과의 친분은 3 명(1.2\%) 로 가장 낮은 것으로 조사되었다.

\section{2. 변수 선정의 타당성 및 신뢰도}

1) 서비스요인에 대한 타당성 및 신뢰도 검증

피부미용실 서비스요인과 관련하여 16 개의 문항에 대한 요인 분석을 실시한 결과는 Table 4 와 같다. 요인분석 결과 4 개의 요 인이 도출되었고 요인의 누적분산설명력은 $87.034 \%$, 신뢰도계 수는 0.8 이상으로 신뢰할 만한 수준이라고 할 수 있다.
2) 관계품질에 대한 타당성 및 신뢰도 검증

관계품질에 대한 요인분석 결과는 Table 5 와 같다. 총 5 개의 문항에 서 2 개의 요인이 도출되었다. 요인의 누적분산설명력은 $78.711 \%$ 로 나타 났으며, 신뢰도 계수는 0.7 이상으로 신뢰할 만한수준이라고 할수 있다.

3) 행동의도에 대한 타당성 및 신뢰도 검증

행동의도에 대한 요인분석 결과는 Table 6 과 같다. 총 5 개의 문항 에서 2 개 요인으로 도출되었고 요인의 누적분산설명력은 $73.813 \%$ 로 나타났으며 신뢰도 계수는 0.6 이상으로 신뢰할 만한 수준이라고 할 수 있다.

\section{3. 각 변수간의 상관관계 및 영향 분석}

1) 상관관계 분석

각 변수 간의 상관관계 분석을 실시한 결과는 Table 7과 같다. 분

Table 6. Analysis of validity and reliability on behavior intention

\begin{tabular}{lcc}
\hline \multirow{2}{*}{ Status } & \multicolumn{2}{c}{ Ingredients } \\
\cline { 2 - 3 } Recommend skin-care shop to others & Word-of-mouth intention & Revisit \\
Tell positive stories on skin-care shop to others & 0.950 & 0.115 \\
Continue visiting skin-care shop & 0.924 & 0.094 \\
Choose this skin-care shop among all others & 0.305 & 0.818 \\
Keep visiting of this skin-care shop even if prices are high & 0.101 & 0.777 \\
Eigen value & 2.572 & 0.688 \\
Variance explanation (\%) & 37.353 & 1.119 \\
Cumulative explanation (\%) & 37.353 & 36.461 \\
Credibility & 0.679 & 73.813 \\
\hline
\end{tabular}

Table 7. Correlation among the variables

\begin{tabular}{|c|c|c|c|c|c|c|c|c|c|}
\hline \multirow{2}{*}{ Status } & & \multicolumn{4}{|c|}{ Service factors } & \multicolumn{2}{|c|}{ Relationship quality } & \multicolumn{2}{|c|}{ Behavior intention } \\
\hline & & Specialization & Market price & Corporality & $\begin{array}{l}\text { Customer } \\
\text { orientation }\end{array}$ & $\begin{array}{l}\text { Customer } \\
\text { satisfaction }\end{array}$ & $\begin{array}{l}\text { Customer } \\
\text { immersion }\end{array}$ & $\begin{array}{l}\text { Word-of-mouth } \\
\text { intention }\end{array}$ & Revisit \\
\hline \multirow{4}{*}{$\begin{array}{l}\text { Service } \\
\text { factors }\end{array}$} & Specialization & 1 & & & & & & & \\
\hline & Market price & $0.330^{* * *}$ & 1 & & & & & & \\
\hline & Corporality & $0.188^{* * *}$ & $0.121^{*}$ & 1 & & & & & \\
\hline & $\begin{array}{l}\text { Customer } \\
\text { orientation }\end{array}$ & $0.218^{* * *}$ & $0.513^{* * *}$ & $0.253^{\star * \star}$ & 1 & & & & \\
\hline \multirow{2}{*}{$\begin{array}{l}\text { Relationship } \\
\text { quality }\end{array}$} & $\begin{array}{l}\text { Customer } \\
\text { satisfaction }\end{array}$ & -0.031 & $-0.225^{* * *}$ & $0.109^{*}$ & $-0.252^{\star \star \star}$ & 1 & & & \\
\hline & $\begin{array}{l}\text { Customer } \\
\text { immersion }\end{array}$ & $0.155^{* *}$ & $0.264^{* * *}$ & $0.165^{* * *}$ & $-0.263^{* * *}$ & $0.257^{* * *}$ & 1 & & \\
\hline \multirow{2}{*}{$\begin{array}{l}\text { Behavior } \\
\text { intention }\end{array}$} & $\begin{array}{l}\text { Word-of-mouth } \\
\text { intention }\end{array}$ & $0.466^{\star * *}$ & $0.665^{* * *}$ & -0.072 & $0.349^{\star * \star}$ & $-0.156^{\star *}$ & $0.132^{* *}$ & 1 & \\
\hline & Revisit & $0.289^{* * *}$ & $0.457^{* * *}$ & $0.341^{* * *}$ & $0.315^{* * *}$ & $0.338^{* * *}$ & $0.115^{*}$ & $0.400^{* * *}$ & 1 \\
\hline
\end{tabular}

${ }^{*} p<.1,{ }^{* *} p<.05,{ }^{* * *} p<.01$ 
석결과 관계마케팅의 실행요인인 서비스요인(전문성, 가격성, 유 형성, 고객지향)과 관계품질(만족, 몰입)이 고객행동의도(구전, 재 이용)에 유의미한 정(+)적 상관관계가 있는 것으로 나타났다. 서비 스요인과 관계품질이 상승할수록 고객행동의도도 비례하여 높아지 는 것으로 나타났다.

\section{2) 서비스요인이 관계품질에 미치는 영향}

피부미용실의 서비스요인이 관계품질에 미치는 영향을 다중 회귀분석을 통해 분석한 결과는 Table 8과 같다. 관계품질과 서 비스요인의 영향관계 분석결과, 만족은 서비스요인 중 유형성( $\beta$ $=0.178, p<.05)$ 이 긍정적인 영향을 주는 것으로 나타났으며 설명 력은 $10.8 \%$ 으로 나타났다. 몰입의 경우 가격성 $(\beta=0.523, p<.01)$, 유형성 $(\beta=0.242, p<.01)$ 이 긍정적인 영향을 미치는 것을 알 수 있 으며 설명력은 $34.8 \%$ 으로 나타났다. 위의 결과를 통해 피부미용 실에서의 서비스요인이 관계품질에 영향을 미치는 것을 확인할 수 있었으며, 특히 서비스요인 중에서는 유형성이 관계품질(만족, 몰 입)에 결정적 역할을 미치는 것을 알 수 있었다.

Lee \& Kim (2005)의 피부미용실의 서비스품질인 전문성과 고 객응대, 물리적 환경이 고객만족에 긍정적인 영향을 미쳤다는 연 구와 Roh (2004)의 스포츠센터 소비자의 서비스 품질지각과 서비
스 가치, 고객만족 및 재이용의사의 관계에서 서비스 품질지각은 고 객만족에 정적인 영향을 미치는 것으로 나타난 연구 등 선행연구와 동일한 결과를 확인하였다.

\section{3) 서비스요인이 고객행동의도에 미치는 영향}

피부미용실의 서비스요인과 고객행동의도 간의 관계를 분석한 결과는 Table 9 와 같다. 고객행동의도 요인 중 재이용의도에 영향 을 미치는 서비스요인으로는 가격성 $(\beta=0.566, p<.01)$, 전문성( $\beta$ $=0.309, p<.01)$, 고객지향 $(\beta=0.044, p<.01)$ 순으로 유의한 긍정적 영향을 미쳤으며 설명력은 $55.1 \%$ 로 나타났다. 구전의도에서는 가 격성 $(\beta=0.371, p<.01)$, 유형성 $(\beta=0.267, p<.01)$, 전문성 $(\beta=0.109$, $p<1$ 이 유의한 긍정적 영향을 미쳤으며 설명력은 $30.3 \%$ 로 나타났 다. Yoo \& Park (1998)은 서비스품질의 효과는 광고의 효과와 마찬 가지로 누적적이기 때문에 서비스품질이 효과를 당장 확인하기는 매우 어려우나 서비스품질이 향상되면 소비행동 즉 재구매와 구전 의도에 영향을 준다고 하여 본 연구와 동일한 결과를 확인하였다.

따라서 피부미용실은 서비스요인의 향상방안을 강구하고, 고객맞춤 서비스를 제공하여 고객과의 지속적인 관계유지를 통해 재이용의도와 구전의도를 높일 수 있는 방안을 마련하는데 노력해야 할 것이다.

Table 8. The influence of service factors on relationship quality in skin-care shop

\begin{tabular}{|c|c|c|c|c|c|c|}
\hline \multicolumn{2}{|c|}{ Dependent variable } & Independent variable & $\beta$ & $F$ & $\mathrm{R}^{2}$ & $p$ \\
\hline \multirow{8}{*}{$\begin{array}{l}\text { Relationship } \\
\text { quality }\end{array}$} & \multirow{4}{*}{$\begin{array}{l}\text { Customer } \\
\text { satisfaction }\end{array}$} & Specialization & 0.032 & \multirow{4}{*}{7.365} & \multirow{4}{*}{0.108} & \multirow{4}{*}{0.000} \\
\hline & & Market price & $-0.138^{*}$ & & & \\
\hline & & Corporality & $0.178^{* *}$ & & & \\
\hline & & Customer orientation & $-0.233^{* * *}$ & & & \\
\hline & \multirow{4}{*}{$\begin{array}{l}\text { Customer } \\
\text { immersion }\end{array}$} & Specialization & 0.069 & \multirow{4}{*}{32.444} & \multirow{4}{*}{0.348} & \multirow{4}{*}{0.000} \\
\hline & & Market price & $0.523^{* * *}$ & & & \\
\hline & & Corporality & $0.242^{* * *}$ & & & \\
\hline & & Customer orientation & $-0.607^{* *}$ & & & \\
\hline
\end{tabular}

${ }^{*} p<.1,{ }^{* *} p<.05,{ }^{* * *} p<.01$

Table 9. The influence of service factors on behavior intention in skin-care shop

\begin{tabular}{|c|c|c|c|c|c|c|}
\hline \multicolumn{2}{|c|}{ Dependent variable } & Independent variable & $\beta$ & $F$ & $\mathrm{R}^{2}$ & $p$ \\
\hline \multirow{8}{*}{$\begin{array}{l}\text { Behavior } \\
\text { intention }\end{array}$} & \multirow{4}{*}{ Revisit } & Specialization & $0.309^{* * *}$ & \multirow{4}{*}{74.607} & \multirow{4}{*}{0.551} & \multirow{4}{*}{0.000} \\
\hline & & Market price & $0.566^{* * *}$ & & & \\
\hline & & Corporality & -0.210 & & & \\
\hline & & Customer orientation & $0.044^{* * *}$ & & & \\
\hline & \multirow{4}{*}{$\begin{array}{l}\text { Word-of-mouth } \\
\text { intention }\end{array}$} & Specialization & $0.109^{*}$ & \multirow{4}{*}{26.350} & \multirow{4}{*}{0.303} & \multirow{4}{*}{0.000} \\
\hline & & Market price & $0.371^{* * *}$ & & & \\
\hline & & Corporality & $0.267^{* * *}$ & & & \\
\hline & & Customer orientation & 0.034 & & & \\
\hline
\end{tabular}

${ }^{*} p<.1,{ }^{* *} p<.05,{ }^{* * *} p<.01$ 
4) 관계품질이 고객행동의도에 미치는 영향

관계품질이 고객행동의도에 영향을 미치는 영향은 Table 10과 같다. 고객행동의도 요인 중에서 재이용의도에 대한 관계품질의 설 명력은 $5.6 \%$ 로 나타났으며, 고객몰입 $(\beta=0.184, p<.01)$ 이 재이용의 도에 유의한 긍정적인 영향을 미치는 결과가 나타났다. 구전의도에 대한 관계품질의 설명력은 $11.5 \%$ 로 나타났으며, 고객만족 $\beta=0.330$ $p$ 〈.01)이 긍정적인 영향을 미치는 것으로 나타났다.

Hong (2006)은 골프연습장 이용자 만족도는 향후 소비자의 재 구매의도 및 구전의도에 정적인 영향을 미친다고 하였고, Chin (2006) 및 Sul \& Moon (2008)은 서비스에 대한 만족은 고객들의 소비행동인 재구매 및 구전의도에 미친다고 하였다. 본 연구와 동 일한 결과를 확인할 수 있었다.

5) 서비스요인과 관계품질이 고객행동의도에 미치는 영향

피부미용실에서의 서비스요인과 관계품질이 고객행동의도에 미 치는 영향을 분석한 결과는 Table 11과 같다. 재이용의도에서는 서비 스요인( $\beta=0.523, p<.01)$ 이 유의한 긍정적 영향을 미치는 것으로 나 타났으며, 구전의도에서는 서비스요인 $(\beta=0.543, p$ 〈.01)과 관계품질 $(\beta=0.329, p<.01)$ 이 유의한 긍정적 영향을 미치는 것으로 나타났다.

\section{Conclusion}

본 연구는 피부미용실에서 서비스요인과 관계품질이 고객행동의 도에 미치는 영향에 대해 알아보고자 성남지역 거주자를 대상으로 설 문조사를 실시하였다. 피부미용실에서의 서비스요인은 전문성, 가격 성, 유형성, 고객지향으로 나타났으며, 관계품질은 만족, 몰입으로
조사되었다. 그리고 고객행동의도는 재이용의도와구전의도로 나타났다. 관계품질 중 고객만족에 영향을 미치는서비스요인으로는 가격성, 유형 성 및 고객지향으로 나타났으며 그 중 유형성이 긍정적인 영향을 미치는 것으로 나타났다. 고객몰입인 경우에는 가격성, 유형성 및 고객지향이 유 의한 영향을 미치며, 가격성 및 유형성이 긍정적인 요인으로 나타났다.

서비스요인이 고객행동의도에 미치는 영향으로 가격성, 전문성 및 고 객지향이 재이용의도에 긍정적인 영향을 미치는 것으로 나타났으며, 반 면 구전의도에서는 가격성, 유형성 및 전문성이 유의한 긍정적 영향을 미치는 것으로 나타났다.

관계품질과 행동의도 간의 영향에 있어서는 고객몰입이 재이용의도 향상에 긍정적인 영향을 미치는 것으로 나타났으며, 구전의도에서는 고객만족이 유의한 긍정적 요인으로 나타났다.

이는 서비스요인과 관계품질이 고객행동의도에 매우 긍정적인 영향 을 미치는 것을 알 수 있었으며, 고객행동의도 중 재이용의도는 서비스 요인, 구전의도는 서비스요인과 관계품질에 긍정적 영향을 받는 것으 로 나타났다.

본 연구를 종합해 보면 피부미용서비스는 전문적인 시술과 함께 무형 적인 서비스가 결합된 것으로 고객이 서비스를 받기 전에는 서비스의 품 질을 알 수 없으므로 적정한 가격, 타 업체와차별화된 시술과 시설 그리 고 고객 편익을 제공하는 물리적 환경 등이 고객만족을 향상시켜 장기적 인 고객과의 관계를 지속시키는 실행요인임을 확인할수 있다. 따라서피 부미용실들은 기존 고객의 재이용의도를 향상시키기 위해서는 다른 서 비스 산업과 마찬가지로 쾌적한 환경, 친절한 직원, 편안한 서비스 공간 등의 유형적 환경과 함께 경쟁업체의 차별화된 시술 등 전문적인 기술 서 비스 제공과 더불어 서비스품질의 향상과 고객만족과 몰입, 신뢰관계의 구축을 통해 재이용의도와 추천의도를 높여야 할 것으로 사료된다.

Table 10. The influence of relationship quality on behavior intention

\begin{tabular}{|c|c|c|c|c|c|c|}
\hline \multicolumn{2}{|c|}{ Dependent variable } & Independent variable & $\beta$ & $F$ & $\mathrm{R}^{2}$ & $p$ \\
\hline \multirow{4}{*}{$\begin{array}{l}\text { Behavior } \\
\text { intention }\end{array}$} & \multirow{2}{*}{ Revisit } & Customer satisfaction & -0.203 & \multirow{2}{*}{7.253} & \multirow{2}{*}{0.056} & \multirow{2}{*}{0.000} \\
\hline & & Customer immersion & $0.184^{* * *}$ & & & \\
\hline & \multirow{2}{*}{$\begin{array}{l}\text { Word-of-mouth } \\
\text { intention }\end{array}$} & Customer satisfaction & $0.330^{* * *}$ & \multirow{2}{*}{15.910} & \multirow{2}{*}{0.115} & \multirow{2}{*}{0.000} \\
\hline & & Customer immersion & 0.030 & & & \\
\hline
\end{tabular}

${ }^{*} p<.1,{ }^{* *} p<.05,{ }^{* * *} p<.01$

Table 11. The influence of service factors and relationship quality on behavior intention

\begin{tabular}{llllll}
\hline Dependent variable & Independent variable & $\beta$ & $F$ & $\mathrm{R}^{2}$ & $p$ \\
& Revisit & Service factors & $0.523^{* * *}$ & & 0.000 \\
$\begin{array}{l}\text { Behavior } \\
\text { intention }\end{array}$ & & Relationship quality & -0.026 & 46.581 & 0.275 \\
& $\begin{array}{l}\text { Word-of-mouth } \\
\text { intention }\end{array}$ & Service factors & $0.543^{* * *}$ & 77.793 & 0.388 \\
& Relationship quality & $0.329^{* *}$ & 0.000 \\
\hline
\end{tabular}

${ }^{*} p<.1,{ }^{* *} p<.05,{ }^{* * *} p<.01$ 


\section{References}

Andreassen TW, Lindestad B. Customer loyalty and complex services: the impact of corporate image on quality, customer satisfaction and loyalty for customers with varying degrees of service expertise. International Journal of Service Industry Management, 9: 7-23, 1998.

Chin $\mathrm{JH}$. Relationship among services quality in the yoga center, customer satisfaction, customers intention to revisit, and word of mouth intention. The Korean Journal of Physical Education, 45: 355-364, 2006.

Choe YH, Rou FR. A study on the effects of the factors of relationship marketing on the loyalty to esthetic salons. Journal of the Korean Society of Cosmetology, 13: 1376-1387, 2007.

Crosby LA, Evans KR, Cowles D. Relationship quality in services selling: an interpersonal influence perspective. Journal of Marketing, 54: 68-81, 1990.

DuPont R. Relationship marketing: a strategy for consumerowned utilities in a restructured industry. Management Quarterly, 38: 11-16, 1998.

Grönroos C. From marketing mix to relationship marketing: towards a paradigm shift in marketing. Management Decision, 32: 4-20, 1994.

Grönroos C. Relationship approach to marketing in service contexts: the marketing and organizational behavior interface. Journal of Business Research, 20: 3-11, 1990.

Han SL. Effects of restaurant service quality on customer retention and word-of-mouth. Journal of Marketing Management Research, 9: 29-46, 2004.

Hong SE. The relationship among service quality of golf driving ranges, service value, user satisfaction, and behavioral intentions. Korean Journal of Sport Management, 11: 1-13, 2006.

Hwang SA, Hwang SJ. The influences of employees' customer orientation and relationship quality (satisfaction, trust, commitment) on revisit intention and word of mouth intention. Journal of the Korea Service Management Society, 6: 151-186, 2005.
Lee KC, Kim SO. A study on the influence of the esthetic salons' service quality upon the customers' satisfaction. Asian Journal of Beauty and Cosmetology, 3: 165-185, 2005.

Morgan RM, Hunt SD. The commitment-trust theory of relationship marketing. Journal of Marketing, 58: 2038, 1994.

Nam HS, Seong HS. Effect of relationship marketing factors at skin care shops on customer satisfaction, customer commitment and the relationship performance. Asian Journal of Beauty and Cosmetology, 12: 435-443, 2014.

Oliver RL. Measurement and evaluation of satisfaction processes in retail settings. Journal of Retailing, 57: 25-48, 1981.

Park SJ. A study on the effects of service quality on customer satisfaction and shop loyalty in the beauty industry. Asian Journal of Beauty and Cosmetology, 8: 353-368, 2010.

Reichheld FF, Sasser WE Jr. Zero defections: quality comes to services. Harvard Business Review, 68: 105-111, 1990.

Roh DY. Relationship among service quality, service value, customer satisfaction and repurchase of sport center consumer. Korean Journal of Sport Management, 9: 71-88, 2004

Sul MS, Moon HJ. The influence of service quality and customer satisfaction on the customer loyalty: a woman participating in aerobic by a leisure activity. Journal of Leisure and Recreation Studies, 32: 71-81, 2008.

Webster FE Jr. The changing role of marketing in the corporation. Journal of Marketing, 56: 1-17, 1992.

Yi YJ. A theoretical examination of customer satisfaction research: findings and outlook. Journal of Consumer Studies, 11: 139-166, 2000.

Yi YJ. Service marketing. Hakhyunsa, Seoul, p304, 2004.

Yoo DK, Park NH. The structural relationship of customer satisfaction and behavioral intentions for service quality. Korean Journal of Hospitality and Tourism, 7: 117-135, 1998. 


\section{국문초록}

\section{피부미용실에서 서비스요인과 관계품질이 고객행동의도에 미치는 영향}

김민정

남서울대학교 경영학과, 충청남도 천안시, 한국

목적: 본 연구는 피부미용실에서 서비스요인과 관계품질이 고객행동의도에 미치는 영향을 알아보고자 한다. 방법: 자료분석은 SPSS Ver. 24 통계 패키지 프로그램을 활용하였다. 빈도분석 후 변수 선정의 타당성 및 신뢰성을 검증하기 위하여 Cronbach's $\alpha$ 와 요인분석을 위해 주성분 분석법과 Varimax를 사용하였다. 또한 변수들 간의 영향을 파악하기 위하여 다중회귀분석을 실시하였다. 결과: 연구결과 서비스요인이 관계품질에 영향을 미치는 것으로 나타났으며, 특히 서비스요인 중에서 유형성이 관계품질에 긍정적 인 영향을 미치는 것을 알 수 있었다. 고객행동의도 중 재이용의도는 서비스요인의 전문성, 가격성 및 고객지향에 긍정적인 영향을 받는 반면 구전의도는 전문성, 가격성 및 유형성에 긍정적인 영향을 받는 것으로 나타났다. 관계품질 중 고객몰입은 재이용의도에 영향을 미치며, 고객만족은 구전의도에 긍정적인 영향을 미치는 것을 확인하였다. 고객행동의도는 서비스요인과 관계품질에 긍정 적인 영향을 받는 것으로 나타났으며, 고객행동의도의 재이용의도는 서비스요인, 구전의도는 서비스요인과 관계품질에 긍정적 영 향을 받는 것을 확인하였다. 결론: 본 연구결과를 통해 피부미용실은 편안한 환경, 친절한 직원 및 서비스 공간과 같은 물리적요인 뿐만 아니라 전문성, 서비스품질 향상, 고객만족과 몰입을 통한 기존 고객의 재이용의도를 높여야 할 것으로 사료된다.

핵심어: 고객행동의도, 고객만족, 고객몰입, 관계품질, 구전의도

\section{참고문헌}

남향숙, 성현선. 피부관리실의 관계마케팅 요인이 고객만족과 관계몰입 및 관계성과에 미치는 영향. 아시안뷰티화장품학술 지, 12: 435-443, 2014.

노동연. 스포츠센터 소비자의 서비스 품질지각과 서비스가치, 고객만족 및 재 이용의사의 관계. 한국스포츠산업경영학회지,

9: 71-88, 2004.

박선주. 미용서비스업의 서비스품질이 고객만족과 점포충성도에 미치는 영향에 관한 연구. 아시안뷰티화장품학술지, 8:

$353-368,2010$.

설민신, 문행자. 상업스포츠센터의 서비스 품질이 고객만족과 고객충성도에 미치는 영향: 여가활동으로 에어로빅스 참여 여

성을 중심으로. 한국여가레크리에이션학회지, 32: 71-81, 2008.

유동근, 박노현. 서비스품질에 따른 고객만족 및 행동의도의 구조적 관계. 호텔경영학연구, $7: 117-135,1998$.

이기채, 김선옥. 피부미용실의 서비스품질이 고객만족에 미치는 영향. 아시안뷰티화장품학술지, 3: 165-185, 2005.

이유재. 고객만족 연구에 관한 종합적 고찰. 소비자학연구, 11: $139-166,2000$.

이유재. 서비스 마케팅. 학현사, 서울, p304, 2004.

진지형. 요가센터의 서비스품질, 고객만족, 재이용의도, 구전의도의 관계. 한국체육학회지, $45: 355-364,2006$.

최영화, 류화라. 관계마케팅 요인이 피부관리실 애호도에 미치는 영향. 한국미용학회지, 13: 1376-1387, 2007.

한상린. 레스토랑의 서비스품질이 고객유지와 구전에 미치는 영향: 관계적 요인의 매개효과를 중심으로. 마케팅관리연구, 9 :

$29-46,2004$.

홍설의. 골프연습장 서비스품질, 서비스가치, 이용자 만족도, 행동의도의 인과관계 분석. 한국스포츠산업경영학회지, 11:1-13, 2006. 황선아, 황선진. 종업원의 고객지향성에 따른 관계 질(만족, 신뢰, 몰입)이 재방문의도에 미치는 영향에 관한 연구. 서비스경 영학회지, 6: 151-186, 2005. 


\section{中文摘要}

\section{服务因素与关系品质对皮肤美容店顾客行为意向影响的研究}

金珉廷

南一大學 经营學科, 忠清南道 天安市, 韩国

目的: 探索在皮肤美容店中, 服务因素与关系品质对顾客行为意向的影响。方法: 利用 SPSS Ver. 24统计软件分析数据。 频率分析结束后, 为鉴定变数选定的妥当性和可靠性利用Cronbach's $\alpha$ 进行分析, 以及利用主成分分析法和Varimax旋转 进行因子分析。利用多元线性回归分析检查变量之间的影响。结果：服务因素影响关系品质，特别是在服务因素中类型 对关系品质产生积极影响。顾客行为意向中, 再访问意图所受服务因素的专业化, 价格以及顾客意向的积极影响。相反 口碑传播意愿则受专业化，价格，类型的影响。关系品质中，顾客投入对再访问意图产生影响，顾客满足对口碑传播意 愿产生影响。顾客行为意向所受服务因素和关系品质的积极影响, 顾客行为意向的再访问意图所受服务因素的影响, 碑传播意愿所受服务因素和关系品质的影响。结论：皮肤美容室不仅向顾客提供安逸的环境，亲切的职员以及服务空间 等物理因素，还需提高专业化，服务品质的上升，满足及吸引顾客从而提高老顾客的再访问。

关键词: 顾客行为意向，顾客满足，顾客投入，关系品质，口碑传播意愿 